\title{
Association of sputum conversion and outcome with initial smear grading among new smear positive Tuberculosis patients in a Tertiary Health Facility, South East Zone, Nigeria
}

\author{
Nwokeukwu H. I., Awujo D. N. and Emma-Ukeagbu U. \\ Department of Community Medicine, Federal Medical Centre, PMB 7001, Umuahia, Abia State, Nigeria
}

\begin{abstract}
Objective: To identify the influence of sputum grading on conversion and cure rate Methodology: It is retrospective study. The new smear positive patients their initial smear grading, conversion and outcome were recorded. The data were collected and analyzed with Excel and Epi info Result: Total number of TB patients collected 208 out of which sputum grading scanty $14 \%, 1^{+} 43 \%, 2^{+} 21 \%$ and $3^{+} 22 \%$. The conversion rates for Scanty $83 \%, 1+84 \%, 2+81 \%$ and $3+72 \% p$. value $>.05$ while the success rate is scanty $93 \%, 1+$ $89 \%, 2+88 \%$ and $3+72 \%$ with $p$. value $<.05$. The mortality rate among sputum grading, scanty $0 \%, 1+3 \%$, $2+7 \%$ and $3+15 \%$. value <.05. Conclusion: The conversion rate of sputum is associated with initial sputum grading. The conversion rate is reduced in sputum grade of $3+$ although there was increase in the conversion rate from scanty to $1+$. The success rate in treatment of $T B$ reduces with increase in the grading and mortality increases. It may be necessary to consider the sputum grading in the treatment of patients.
\end{abstract}

Key words: Sputum conversion, outcome, smear grading and tuberculosis

\section{Introduction}

Tuberculosis (TB) is one of the re-emerging diseases of public health importance, especially with the pandemic of HIV. It has been estimated that someone in the world is newly infected with TB every second, nearly $1 \%$ of the world population gets infected with TB every year and overall, one third of the world population is infected with Mycobacterium $\mathrm{TB}^{1,2,3,4}$ All countries are affected, 30\% in Africa, 55\% in Asia. 22 high-burden countries account for $80 \%$ of world's TB. The diagnosis of TB according to the TBL control programme can be made with identification of acid-fast bacilli using a Ziehl Nelson stain. The sputum result is based on the number of acid-fast bacilli per oil immersion field. The different grades from the smear indicate the different levels of the bacillary load. The available and reliable instrument used in diagnosis of tuberculosis in the resource limited country is still sputum smear microscopy. This is unlike what we have in developed world with availability of other instrument in adequate quantity in detecting mycobacterium tuberculosis like Gene Xpert MTB/RIF assay, fluorescent microscopy, loop mediated isothermal amplification assay, line probe assays and culture and sensitivity test ${ }^{5}$. The use of Gene Xpert MTB/RIF in this part of the world is limited to cases of suspected MDR-TB where the patients had taken both category 1 and 2 . The culture and sensitivity testing is not located in the South East Zone but in another zone of the country as at the time of this Study. The best test that could be used was sputum AFB microscopy.

The dosing of treatment of tuberculosis is based on the pre-treatment weight of the patients not on sputum result. These sputum grades signifying different levels of the bacillary load are however not taken into account as a guide for the dose of drugs, duration of therapy, or further monitoring of the therapy whereas, several studies in the past have reported unfavorable treatment outcomes increasing with increasing grades of sputum positivity. ${ }^{6,7,8}$. It was therefore very important to have carried out this study to be able to know actually if sputum grading has association with sputum conversion rates and treatment outcomes especially with the challenges in the control of Tuberculosis with increase in Multi-Drug resistant Tuberculosis (MDR-TB).

\section{Methods}

A retrospective study conducted in DOTs centre of Federal Medical Centre, Umuahia, Abia State, South East Zone, Nigeria.

Inclusion Criteria: All new smear positive patients (2010 and 2011) were included and their initial sputum grading, conversion and outcome were collected from the records .

Exclusion Criteria. The sputum negative and extra pulmonary tuberculosis were excluded in the study.

The sputum was collected from patients at the diagnosis Spot, Early morning and Spot while in follow up for determining the conversion of the sputum, two early morning sputum for two days were collected.

The sputum grading were scanty, $1+, 2+$ and $3+$. Scanty means 1 to 9 AFB in 100 oil immersion fields.1+ means 10-99 AFB in 100 oil immersion fields. 2+ means 1 to 10 AFB per oil immersion field in at least 50 fields. $3+$ is more than 10 AFB per oil immersion field in at least 20 fields. 
Data analysis: A total of 208 patients that were sputum smear positive were studied. The monitoring of treatment for patients was assessed at recommended programme intervals: at the second/third month, fifth and seventh months of treatment for presence or the absence of acid fast bacilli using Ziehl Nelson stain. Smear conversion is accepted as having occurred when first of the two serial negative smears for AFB from initiation of treatment was gotten. The success rate included those who were sputum positive at diagnosis and completed their treatment (the result of sputum after 7 months not recorded but had been negative in previous test 2/3 and 5 months) and those declared cured (sputum AFB negative at 7 months and at least one previous result)

The treatment was in two phases (intensive and continuation) for eight months. During the intensive phase four drugs were used Pyrizanimide, Isoniazid, Rifampicin and Ethambutol given in Fixed preparation for 2months; if no conversion it is extended to three months. The dose is based on the weight of the patient according to WHO recommendation. The continuation phase was with two drugs; also Fixed combinationIsoniazid and Ethambutol for 6 months if the patient converted at 2 months and 5months if the patient converted at 3 months; all to make up the 8 month regimen which is still being used in this part of the world. HIV counseling and testing were offered to all the patients.

Data was entered and analyzed with Excel and further analyzed using EPI Info version 7software. Tests for statistically significant findings were done at $95 \%$ confidence intervals with Chi square tests and $\mathrm{P}$ value of $<0.05$ were considered significant.

\section{Results}

Out of 421 patients enrolled for treatment within that study period of 2010 and 2011, a total number of $208(49.4 \%) \mathrm{Tb}$ patients were new smear positive, out of which initial sputum grading was scanty: $14 \%, 1^{+}$: $43 \%, 2^{+}: 21 \%$ and $3^{+}: 22 \%$.

Most of the patients were male $(56.7 \%)$ except in scanty grading, females were more (55.2\%). Better conversion rates were observed with lesser sputum positivity grading. The conversion rates at 2 months was found to decrease as follows: for Scanty: $83 \%, 1+: 84 \%, 2+: 81 \%$ and $3+: 72 \%$ (p. value $>.05$ ). Conversion rates at 3 months was as follows Scanty : 93.1\%, 1+: $90 \%, 2+: 88.4 \%, 3+: 78.3 \%$ ( p value <.05.)

A patient was declared cured based on negative sputum results attained after the $7^{\text {th }}$ month of treatment and on at least one previous occasion. In this study, the cure rates were better in patients with lesser sputum smear positivity grading. The success rate among sputum grading was scanty $93 \%, 1+89 \%, 2+88 \%$ and $3+$ $72 \%$ with p. value $<.05$.

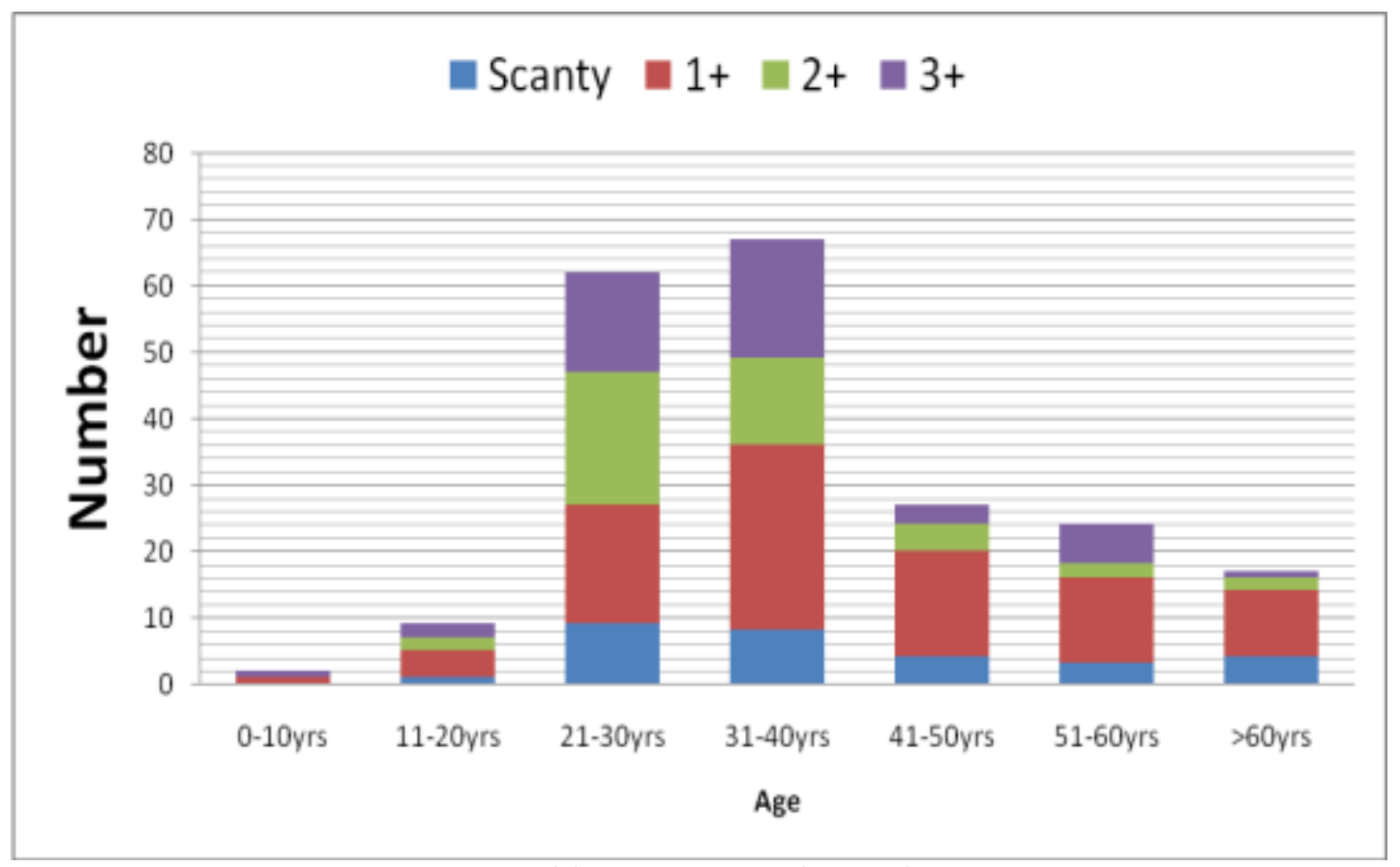

Figure 1: Initial sputum grading against age

The above figure showed that most of the patients were within the age group of 21-40years. Sputum grading of $1+$ and $3+$ were more within the age group of 31-41years while Scanty and 2+ are more within age group 2130years. 


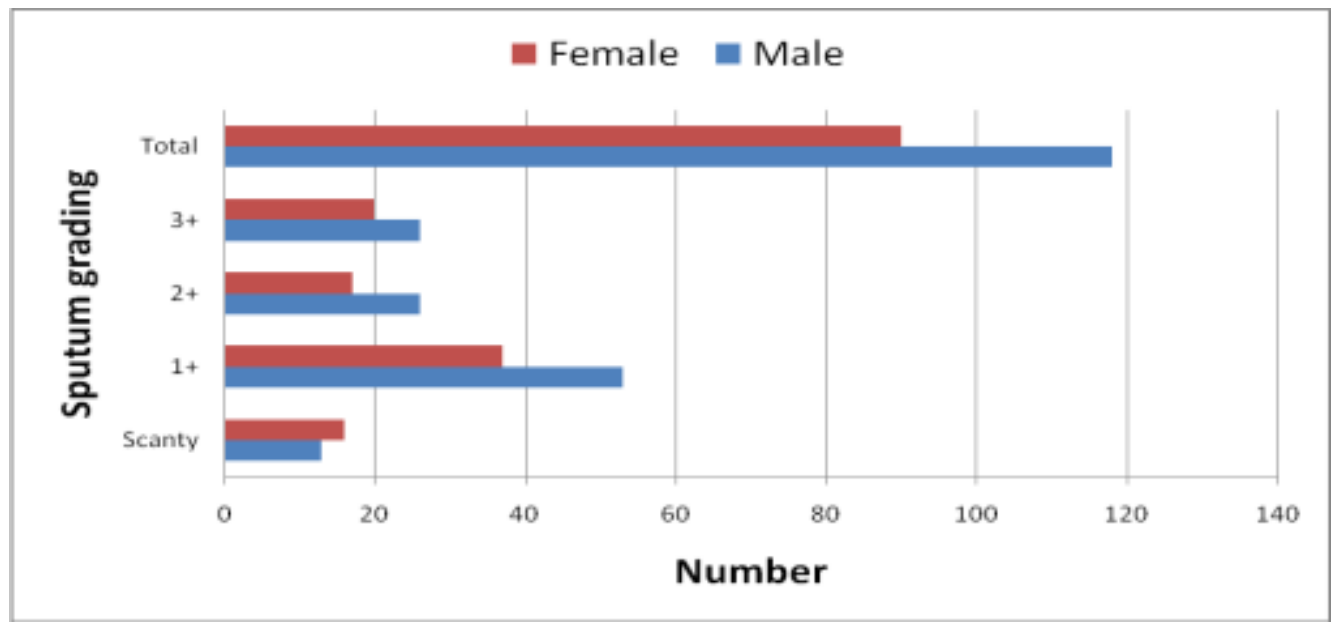

Figure 2: Sex against initial smear grading

It showed more males being affected than females in all the sputum grading except in scanty grade where females are more.

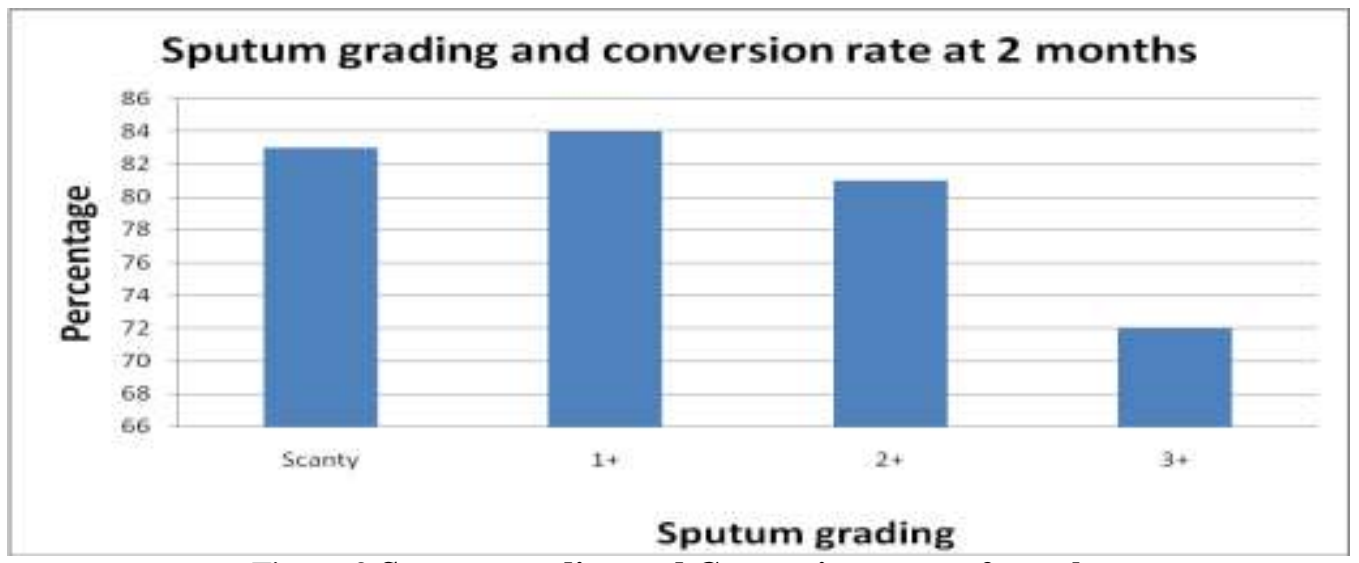

Figure 3:Sputum grading and Conversion rate at 2months

The figure three showed the sputum conversion rate reduced with increase sputum grading except in $1+$ in which there was a slight increase from scanty to $1+$.

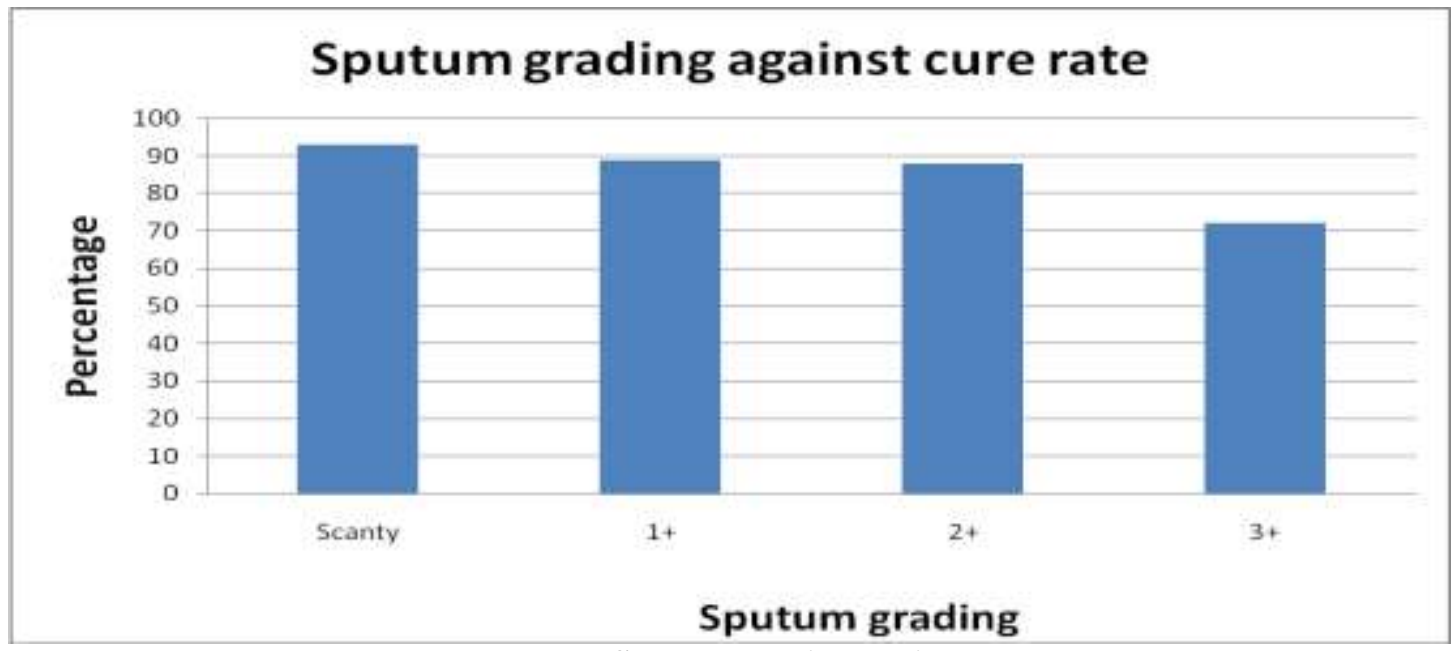

Figure 4: Sputum grading against cure rate

In the above figure there was reduction in cure rate with increase in sputum grading. The scanty had highest cure rate $(93 \%)$ and $3+$ lowest cure rate $(72 \%)$. 


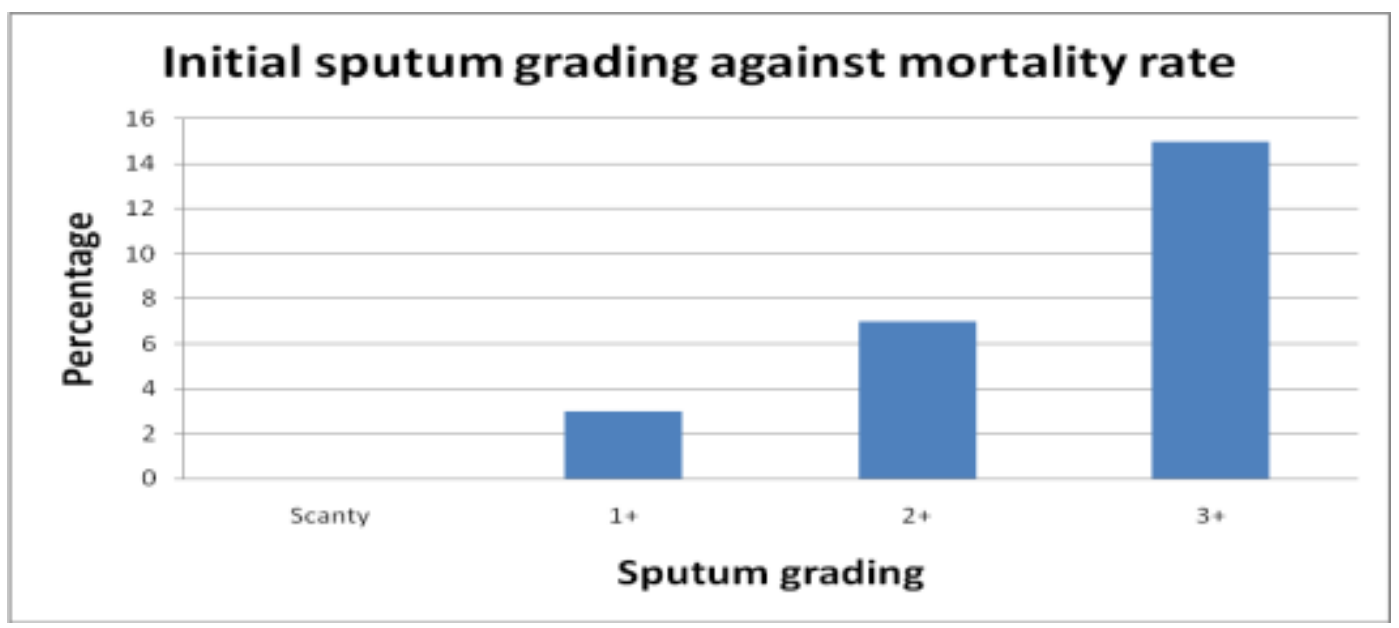

Figure 5: Initial sputum grading against mortality rate

The mortality rate increased with the sputum grading scanty: $0 \%, 1+: 3 \%, 2+: 7 \%$ and $3+: 35 \%$

Table 1: Sputum conversion rates and treatment outcome of patient under study

\begin{tabular}{|l|l|l|l|l|l|l|l|l|}
\hline $\begin{array}{l}\text { Initial } \\
\text { sputum } \\
\text { grading }\end{array}$ & $\begin{array}{l}\text { Conversion } \\
\text { at 2months }\end{array}$ & $\begin{array}{l}\text { Conversio } \\
\mathrm{n} \text { at } \\
\text { 3months }\end{array}$ & $\begin{array}{l}\text { Outcome } \\
\text { Success rate }\end{array}$ & Died & Failed & $\begin{array}{l}\text { Default } \\
\text { ed }\end{array}$ & $\begin{array}{l}\text { Transfer } \\
\text { out/others }\end{array}$ & $\begin{array}{l}\text { Total no of } \\
\text { patients }\end{array}$ \\
\hline $\begin{array}{l}\text { Group i: } \\
\text { scanty }\end{array}$ & $24(82.8)$ & $27(93.1)$ & $27(93.1)$ & $0(0)$ & $0(00$ & $2(6.9)$ & $0(0)$ & $29(13.9)$ \\
\hline Group ii: 1+ & $76(84.4)$ & $81(90.0)$ & $80(88.9)$ & $3(3.3)$ & $3(3.3)$ & $3(3.3)$ & $1(1.1)$ & $90(43.3)$ \\
\hline Group iii:2+ & $35(81.4)$ & $38(88.4)$ & $38(88.4)$ & $3(7.0)$ & $0(0)$ & $2(4.7)$ & $0(0)$ & $43(20.7)$ \\
\hline $\begin{array}{l}\text { Group iv: } \\
\text { 3+ } 33(71.7)\end{array}$ & $36(78.3)$ & $33(71.1)$ & $7(15.2)$ & $0(0)$ & $\begin{array}{l}5 \\
(10.9)\end{array}$ & $1(2.2)$ & $46(22.1)$ \\
\hline $\begin{array}{l}\text { Group v: } \\
\text { summation } \\
\text { of group i to } \\
\text { iii }\end{array}$ & $135(83.3)$ & $146(90.1)$ & $145(89.5)$ & $6(3.7)$ & $3(1.9)$ & $7(4.3)$ & $10(0.6)$ & $162(77.9)$ \\
\hline
\end{tabular}

Table 2: Grouped Sputum smear grading and treatment outcome

\begin{tabular}{|l|l|l|l|}
\hline & $\begin{array}{l}\text { Sputum } \\
\text { smear of < or } \\
=2+ \\
\mathrm{N}(\%)\end{array}$ & $\begin{array}{l}\text { Sputum } \\
\text { smear of 3+ } \\
\text { N }(\%)\end{array}$ & P value \\
\hline $\begin{array}{l}\text { Conversion } \\
\text { at 2months }\end{array}$ & $135(83.3)$ & $33(71.7)$ & 0.06 \\
\hline $\begin{array}{l}\text { Conversion } \\
\text { at 3months }\end{array}$ & $146(90.1)$ & $36(78.3)$ & $0.03^{*}$ \\
\hline $\begin{array}{l}\text { Treatment } \\
\text { success }\end{array}$ & $145(89.5)$ & $33(71.1)$ & $.003^{*}$ \\
\hline Died & $6(3.7)$ & $7(15.2)$ & $.005^{*}$ \\
\hline Failed & $3(1.9)$ & $0(0)$ & 0.4 \\
\hline Defaulted & $7(4.3)$ & $5(10.9)$ & $0.009^{*}$ \\
\hline $\begin{array}{l}\text { Transfer } \\
\text { out/others }\end{array}$ & $10(0.6)$ & $1(2.2)$ & 0.39 \\
\hline Total & $162(77.9)$ & $46(22.1)$ & \\
\hline
\end{tabular}

In the above table the sputum grading and conversion at two month had p value 0.06 while that of three month is statistically significant with $\mathrm{p}$ value of 0.03 . The sputum grading and treatment outcome is statistically significant for success, mortality rates and default with p values of $.003, .003$ and .009 respectively.

\section{Discussion}

The study showed that most of the patient's sputum grading were $1+$, most affected age group of 2140years and there was a higher proportion of males. This can be associated with HIV occurring in the active 
sexual age. The same is reported in study done in India. ${ }^{9}$ AFB (acid-fast bacilli) in sputum smear is the diagnostic test with $95.6 \%$ specificity. ${ }^{9}{ }^{90}$ Therefore, sputum AFB conversion is a suitable indicator to evaluate the treatment response. ${ }^{11}$ The grading of a positive smear reflects the extent of lesion in a particular patient or size of cavitations as well as being directly proportional to the infectiousness of the case. ${ }^{12}$ In this study, the presence of numerous bacilli (3+) on initial pre-treatment sputum smears was a predictor of non conversion of positive sputum smears after two months of anti tuberculosis therapy. These finding is similar to previous studies. ${ }^{13,14}$

In this study patients with higher sputum smear grading had poorer treatment outcomes (lower treatment success rate, high mortality) Studies have also shown that non conversion of positive smears at the end of two months of treatment is one of the strongest predictors for treatment failure. ${ }^{15,16}$ This study has shown that, it may not be the only predictors for treatment failure; but sputum grading may also be contributory. There was reduction in conversion rate with increase in initial sputum grading, showing that sputum grading affects the conversion rate. This is similar to some previous studies. ${ }^{6,12,17}$.

The treatment outcome was also compared with the initial sputum grading. In the outcome, cured was summed with treatment completed to give the success rate. The success rate reduced with the increase in the initial sputum grading. $3+$ success rates was low when compared with scanty, $1+$ and $2+(\mathrm{P}$ value $<.05)$ as shown in "Table 1". This result is similar to some studies. ${ }^{7,9}$ A higher proportion of deaths was seen in patients with $3+$ grading of sputum. The mortality rate among the $3+$ patients was about four times that of scanty, $1+$ and $2+$ added together ( $\mathrm{P}$ value 0.005 ). The defaulter rate and transfer out/others were still higher in the patients with initial sputum grading of $3+$; similar in other studies. ${ }^{12,14}$

\section{Conclusion}

The conversion rate of sputum is associated with initial sputum grading. There is undeniable evidence that patients with higher sputum grading before treatment have an increased risk of poor outcome than their counterparts with lower smear grading. The conversion rate and success rate also reduced with increased sputum grading. Increased mortality was also directly proportional to initial sputum grading.

It is therefore recommended that early identification of patients who may have an increased risk of a poor outcome such as high sputum smear grading should be coupled with interventions, such as treatment modification and closer monitoring to reduce the potential of poorer treatment outcomes. It may be necessary to consider the sputum grading in the treatment of patients. The patients with high sputum grading will be better managed as In-patient or DOTs for also the duration of continuation phase of treatment.

Conflict of Interest: The authors have no conflict of interest to declare.

Acknowledgement:

All the staff of Community Medicine Department and TB laboratory of Federal Medical Centre, Umuahia, Abia State and Ministry of Health TB division for the generation of the data in the records.

\section{References}

[1] Raviglione MC, Snider DE, Jr, Kochi A. Global epidemiology of tuberculosis: morbidity and mortality of a worldwide epidemic. JAMA. 1995;273:220-6.

[2] Murray GDL, Styblo K, Rouillon A. Tuberculosis in developing countries: burden. intervention and cost. Bull Int Union Tuberc Lung Dis. 1990;35:25-35.

[3] Murray CJL, Styblo K, Rouillon A. Tuberculosis in developing countries: burden, intervention and cost. Bull Int Union Tuberc lung Dis. 1990;65:6-24.

[4] WHO. TB fact sheet. http://www.who.int/tb/publications/factsheets/en/index.html

[5] Hsien- Holin, David Dowdy, Christopher Dye, Megan Murry, Ted Cohen: The impact of new tuberculosis diagnostics on transmission: why context matters: WHO Bulletin $2011 \mathrm{pg} \mathrm{1-10} \mathrm{http://www.who.int/bulletin/volumes/90/10/11-101436.pdf}$

[6] Singla R, Singla N, Sarin R, Arora VK. Influence of pretreatment bacillary load on treatment outcome of pulmonary tuberculosis patients receiving DOTS under the Revised National Tuberculosis Control Programme. Indian J, Chest Dis and Allied Sci 2005;47:19-23.

[7] Gopi PG, Chandrasekaran V, Subramani R, Santha T, Thomas A, Selvakumar N, et al. Association of conversion and cure with initial smear grading among new smear positive pulmonary tuberculosis patients treated with Category I regimen. Tuberculosis Research Centre (ICMR) Chennai, India. Indian J Med Res 2006;123:807-14.

[8] .Mukherjee A, Singla R, Saha I, Sarkar A, Bhattacharyya P. Difference in the Outcome of Patients with Different Grades of Initial Sputum Positivity under the Revised National Tuberculosis Control Programme .Indian J Chest Dis Allied Sci 2011;53:241 242.

[9] . Bawri S, Ali S., Phukan C, Tayal B and Baruwa P. A Study of Sputum Conversion in New Smear Positive Pulmonary Tuberculosis Cases at the Monthly Intervals of $1^{\text {st }}, 2^{\text {nd }} \& 3^{\text {rd }}$ Month Under Directly Observed Treatment, Short Course (Dots) Regimen. http//www.ncbi.nlm.nih.gov/pmc/articles/pmc2822329 8.

[10] . Mfinanga GS, Ngadaya E, Mtandu R, Mutayoba B, Basra D, Kimaro G, et al. The quality of sputum smear microscopy diagnosis of pulmonary tuberculosis in Dares Salaam, Tanzania. Tanzan Health Res Bull. 2007; 9:164-168.

[11] .Lawson L, Yassin MA, Ramsay A, Olajide I, Thacher TD, Davies PD, et al. Microbiological validation of smear microscopy after sputum digestion with bleach; a step closer to a one-stop diagnosis of pulmonary tuberculosis. Tuberculosis (Edinb). 2006; 86:34-40. 
[12] Liu Z, Shilkret KL, Ellis HM. Predictors of sputum conversion among patients with tuberculosis in the era of tuberculosis resurgence. Arch Intern Med 1999; 159:1110-1116.

[13] Sanjay Rajpal, Dhingara VK. \& Agarwal JK:Sputum grading as predictor of treatment outcome in pulmonary tuberculosis. Ind J Tub. 2002;49:139-141

[14] . C. Kuaban, R. Bame, L. Mouangue, S. Djella and C. Yomgni. Non conversion of sputum smears in new smear positive pulmonary tuberculosis patients in Yaoundé, Cameroon. East African Medical Journal;2009: 86 ( 5 )

[15] Su W-J., Feng J-Y, Chiu Y-C, Huang S-F, Lee Y-C. Role of 2-month sputum smears in predicting culture conversion in pulmonary tuberculosis. ERJ ,2011; 37( 2):376-383.

[16] Chavez, Pachas, A.M., Blank, R., Smith, Fawzi, M.C. Identifying early treatment failure on category 1 therapy for pulmonary tuberculosis in Lima Ciudad, Peru. Int. J. Tuberc. Lung Dis. 2004; 8:52-58.

[17] Banu Rekha V.V, Balasubramanian R, Swaminathan S, Ramachandran R Fathima Rahman, V. Sundaram, K.Thyagarajan et al Sputum conversion at the end of intensive phase of Category-1 regimen in the treatment of pulmonary tuberculosis patients with diabetes mellitus or HIV infection: An analysis of risk factors. Indian J Med Res , 2007; 126: 452-458 